\title{
FLASH AESTHESIS: UMA NEUROFILOSOFIA DA EXPERIÊNCIA ESTÉTICA
}

\author{
Ronaldo BISPO ${ }^{1}$
}

- RESUMO O texto a seguir apresenta em diálogo ou aplica a uma certa concepção de experiência estética um amplo conjunto de evidências experimentais retirado da investigação de outros fenômenos mentais, em particular a experiência subjetiva de emoções e sentimentos. Provém de António Damásio a viga mestra, o esqueleto, a base, a estrutura de toda a minha argumentação. Minha principal hipótese é a de que certos objetos e situações ativam hiper-espaços dispositivos cerebrais associados à ocorrência de fenômenos como sensação de beleza, prazer e alegria. Proponho que a emergência de uma experiência estética deve ser compreendida como resultado de uma percepção sensível que aciona uma rotina somático-cognitiva, função do disparo de um padrão de padrões neurais dispositivos.

- PALAVRAS-CHAVE: experiência estética; sentimento; hiper-espaço; neurofilosofia; cérebro

\section{Introdução}

X foi à apresentação de um DJ de Hard Techno em um galpão no bairro da Barra Funda em São Paulo. Lá, entre muitas beldades, foi atraído particularmente por uma garota, o modo como dançava, a roupa que vestia, as características físicas, o tipo e o corte de cabelo, a semelhança entre os movimentos do corpo e as batidas da música.

1 Professor da Universidade Federal de Alagoas. 
No curso de nossas vidas nos deparamos com certas coisas que chamam, atraem a nossa atenção. Diante destas somos tomados por uma sensação particular. A reação mais comum a essas percepções é a atitude de permanecer mais um pouco afetados por elas. Não queremos abandoná-las, desejamo-las porque sob sua influência nos sentimos bem ou porque algo como uma especial intensidade se faz sentir.

Acredito poder incluir o fenômeno geral descrito acima, e seu exemplo específico, como um caso do que denomino de pequena experiência estética instantânea, estetização automática ou flash aesthesis: ${ }^{2}$ toda percepção sensível de um objeto ou situação que ativa uma rotina somática e/ou cerebral imediata tal que induz a alguns dos seguintes afetos e/ou cognições: alegria, prazer, interesse, vontade de vida, beleza, atenção/concentração, vivacidade, lágrima nos olhos, sorriso no rosto, rápida associação de idéias e sentimentos, vontade de permanecer sob o efeito do objeto, etc. Cabe agora então sugerir uma explicação geral para o fenômeno: como e por que o corpo de $\mathrm{X}$ reagiu daquele modo específico diante da garota em questão? Ou de modo mais genérico: como e por que um corpo cria para si uma breve experiência estética automática?

Basicamente o que farei é transpor para o fenômeno da experiência estética um amplo conjunto de evidências experimentais retirado da investigação de outros fenômenos mentais, em particular a experiência subjetiva de emoções e sentimentos. Segundo o ponto de vista adotado aqui, a experiência estética envolve, é constituída por emoções, sentimentos e pensamentos tal como definidos pela neurociência mais recente. Neste sentido, acredito poder sustentar que a experiência estética é também um tipo de sentimento, como alegria, raiva, prazer, ciúme, orgulho ou medo. Muito provavelmente não se trata de um sentimento simples, mas a composição ou co-ocorrência de vários sentimentos simultâneos. Assim, do mesmo modo que dizemos "Estou com medo" ou "Estou com raiva", em algumas ocasiões deveríamos dizer

2 Flash Aesthesis é uma das expressões que proponho para denominar o fenômeno aqui sob investigação. Flash é uma palavra inglesa já incorporada pela língua portuguesa e significa entre outras coisas: clarão rápido e intenso, lampejo, instante, etc. Aesthesis é a palavra grega na origem do vocábulo "estética" e significa percepção sensível, sensibilidade, sentimento, etc. Diferentemente do significado mais comum associado ao conceito de experiência estética, a expressão flash aesthesis parece captar bem as características de instantaneidade, rapidez, superficialidade, fugacidade, intensidade, iluminação, associadas à classe de acontecimento que procuro desvendar. Optei deliberadamente também por multiplicar as denominações do fenômeno estudado acreditando com isto destacar em cada caso uma diferente peculiaridade do mesmo. 
"Estou com estético" ou "Estou estetizado" ou "Estou estético", mas não histérico ou patético. Por conseguinte, aquilo que as pesquisas experimentais têm revelado quanto ao substrato orgânico responsável pelo disparo, execução e percepção de emoções e sentimentos diversos, poderá também servir de base para a compreensão do fenômeno da pequena experiência estética imediata.

Provém de António Damásio a viga mestra, o esqueleto, a base, a estrutura de toda a minha argumentação. Ao longo de seus três livros, Damásio $(1996,2000,2003)$ apresenta o que avalio ser uma teoria consistente sobre a relação entre emoção, sentimento, razão e consciência baseada em estudos neuropsicológicos, neurofisiológicos e neuroanatômicos, e desenvolvida ao longo de anos de pesquisa experimental, curiosidade filosófica e tratamento de pacientes com os mais variados tipos de dano neurológico. É sobretudo nestes livros que encontro os esclarecimentos e argumentos necessários para defender e refinar provisoriamente minha hipótese de trabalho, segundo a qual um corpo constrói para si uma flash aesthesis através da ativação de circuitos e sistemas específicos do corpo e do cérebro, e assim o faz função de determinada predisposição neurofisiológica inata e adquirida.

Dito já em termos damasianos, minha principal hipótese é a de que certos objetos e situações ativam registros dispositivos cerebrais associados a sistemas de gratificação e/ou recompensa. Proponho que a emergência de uma experiência estética tal como definida acima deve ser compreendida como resultado de uma percepção sensível que ativa uma rotina somática função do disparo de um padrão neural dispositivo. Esse padrão neural dispositivo reuniria um conjunto compactado de comandos neurais responsável pelo aparecimento de sentimentos e pensamentos co-associados à percepção de determinado objeto ou situação. Assim sendo, a descrição dos fenômenos acima referidos avançada por Damásio servirá como fio condutor da elaboração de minha própria hipótese para o acontecimento da experiência estética ao qual serão integradas várias outras evidências desenvolvidas por diferentes autores e linhas de pesquisa.

\section{Emoção e sentimento em Damásio}

K estava jogando xadrez com seu amigo X no apartamento deste último em um velho prédio na rua Turiassu, no bairro da Água Branca em São Paulo, quando indagou que "som" era aquele que estavam ouvindo 
no momento. X se levantou, verificou o número da faixa em andamento no CD player, olhou a longa lista de músicas impressa na capa do CD e disse: "Posers da banda Frankenixon. Bom, né?" Ao que $\mathrm{K}$ respondeu: "Nossa, excelente!" Mais algumas jogadas, a música acaba e $\mathrm{K}$ pede para ouvi-la novamente. X assente e $\mathrm{K}$ começa a simular a bateria da música, a balançar mesmo sentado no ritmo da canção e diz empolgado, expressivo: "Lindo isso, lindo! Muito bom! Como é mesmo o nome da banda?" "Frankenixon. Também nunca tinha ouvido falar", responde $\mathrm{X}$. O jogo avança, X está prestes a ganhar, a música termina novamente. $\mathrm{K}$ então pede para repeti-la uma vez mais, só que desta vez já encontra X saturado: "Não, não, não, não, não! Eu gravo para você. Depois você ouve mais". K fica desolado, estava completamente fascinado pela música. Por ele, "mandaria" um repeat e a ouviria muitas e muitas vezes seguidas. Era a primeira vez que entrava em contato com aquela banda.

$\mathrm{O}$ que teria acontecido com $\mathrm{K}$ ? Como e por que exatamente aquela música entre tantas ouvidas causou nele tal reação? Muitas, inúmeras mesmo, são as entradas possíveis para tentar dar conta do fenômeno. Podemos abordar esse acontecimento dos pontos de vista psicológico, cultural, perceptivo, filosófico, descrevendo as características do objeto, etc. A abordagem aqui desenvolvida privilegia, dá atenção especial ao corpo biológico do sujeito, ao aparato perceptual-cognitivo, neurofisiológico, implicado nos encontros citados. Nunca será demais repetir que esse nível de descrição do fenômeno, além de deixar muitas perguntas sem resposta, só tem seu valor assegurado no contexto dos outros níveis descritivos. Por outro lado, negar a relevância da aplicação das descobertas e proposições das ciências cognitivas (neurociência e filosofia da mente em especial) na compreensão da experiência estética é no mínimo preconceito, insegurança, ou mesmo ignorância.

De acordo com minha hipótese, $\mathrm{K}$ foi tomado por uma flash aesthesis, uma estetização instantânea. Como e por que esta teve lugar? Ora, admitindo que a experiência estética é, entre outras coisas, um tipo de sentimento, responder a esta pergunta é, em parte, compreender o que é um sentimento em geral e como este emerge ou tem lugar em um corpo-mente. Para isto, no entanto, é necessário antes entender a relação e distinção entre sentimentos e emoções. Para Damásio, sentimentos são evolutivamente mais recentes que as emoções e, em geral, resultam da percepção destas.

Ao longo de seus três livros de divulgação científica, Damásio aprimorou e refinou sua concepção de emoção em inúmeras definições mais ou menos semelhantes. Em $O$ Erro de Descartes, livro dedicado à 
demonstração do necessário substrato emocional do raciocínio e das tomadas de decisão, lê-se por exemplo:

Vejo a essência da emoção como a coleção de mudanças no estado do corpo que são induzidas numa infinidade de órgãos por meio das terminações das células nervosas sob o controle de um sistema cerebral dedicado, o qual responde ao conteúdo dos pensamentos relativos a uma determinada entidade ou acontecimento. (...) A emoção é a combinação de um processo avaliatório mental, simples ou complexo, com respostas dispositivas a esse processo, em sua maioria dirigidas ao corpo propriamente dito, resultando num estado emocional do corpo, mas também dirigidas ao próprio cérebro (núcleos neurotransmissores no tronco cerebral), resultando em alterações mentais adicionais. (Damásio 1996: 168-9)

Desde esse primeiro livro, portanto, "emoção" é compreendida como o conjunto de mudanças que ocorre quer no corpo quer no cérebro e que normalmente é originado por um determinado conteúdo mental. Em O Mistério da Consciência, tentativa damasiana de dar conta do problema da mente consciente, o autor ocupa-se menos com a definição de emoção, mas ainda assim encontramos uma especificidade adicional de sua concepção:

(...)os estados emocionais são definidos por uma infinidade de mudanças na composição química do corpo, por mudanças no estado das vísceras e por mudanças no grau de contração de diversos músculos estriados do rosto, da garganta, do tronco e dos membros. Mas também são definidos por mudanças no conjunto de estruturas neurais que primeiramente fizeram com que essas mudanças ocorressem e que também causam outras mudanças significativas no estado de vários circuitos neurais no interior do próprio cérebro (Damásio 2000: 357).

Por fim, em seu livro mais recente Looking for Spinoza: Joy, Sorrow and the Feeling Brain, Damásio retoma vigorosamente a investigação dos substratos neurais de nossos sentimentos conscientes e, conseqüentemente, do papel da emoção nesse processo. Aqui as definições se multiplicam e ganham novos matizes: emoção é compreendida, dentre outros modos, como: reação de um organismo a algum estímulo ou percepção interna ou externa; detecção da presença de um objeto ou evento que recomenda evitar e fugir ou aprovar e se aproximar; alteração neuroquímica que precede os sentimentos; ações ou movimentos, a maior parte deles públicos, visíveis aos outros como eles ocorrem na fa- 
ce, na voz e em comportamentos específicos; integrante do teatro do corpo; coleção complexa de respostas químicas e neurais formando um padrão distintivo; construção a partir de reações simples que facilmente promovem a sobrevivência de um organismo e assim prevalecem evolutivamente; maquinaria para produção de reações a um objeto ou evento, direcionado pelo objeto ou pela circunstância.

Dessa reunião de definições é possível depreender alguns aspectos fundamentais. Emoção é o conjunto de alterações orgânicas (ocorridas no corpo e/ou no cérebro) ${ }^{3}$ resultante da percepção de um objeto interno ou externo. Reações emocionais são performances orgânicas orquestradas que visam a corrigir ou sinalizar um estado de desequilíbrio homeostático visando à sobrevivência do organismo. Em grande medida, emoções são disparadas automaticamente diante de certos estímulos, até mesmo sem a necessidade de percepção consciente. Nesse sentido, Damásio sugere denominar como "emoções" ou "reações relacionadas a emoções" inclusive aqueles processos básicos e primitivos de regulação homeostática automatizada da vida tais como: regulação metabólica (secreção hormonal, contrações musculares, pressão sanguínea, estocagem de proteínas); reflexos básicos (sistema imunológico); comportamentos associados à noção de dor e prazer (aproximação e afastamento dos estímulos disparadores); impulsos e motivações (sede, fome, curiosidade, exploração, jogo, sexo) e emoções propriamente ditas ou emoções-próprias (alegria, tristeza, orgulho, vergonha, simpatia). Alguma coisa da maquinaria do sistema imune e da regulação metabólica é incorporada na maquinaria dos comportamentos de dor e prazer. Algo destes últimos é incorporado na maquinaria dos impulsos e motivações, assim como alguma coisa da maquinaria de todos os níveis anteriores é incorporada na maquinaria das emoções-próprias (emotionsproper). Todos esses mecanismos visam ao mesmo objetivo: a manutenção da vida com bem-estar.

E os sentimentos? Para Damásio, os sentimentos são a expressão mental de todos os outros níveis da regulação homeostática. Um sentimento emerge como a percepção consciente das alterações orgânicas que constituem uma emoção. Desnecessário dizer, nem todas as emoções tornam-se sentimentos. Antes de caracterizar mais especifica-

3 Com objetivos metodológicos, o cérebro é considerado uma parte realçada do restante do corpo. É certo que o cérebro integra o corpo, faz parte dele, mas graças a seu papel preponderante no gerenciamento deste, refere-se àquele destacadamente. 
mente os sentimentos, no entanto, vejamos como ocorre uma emoção, como uma reação emocional tem lugar. Dado que o que me interessa aqui é o acontecimento do sentimento estético em um ser humano, concentrarei a exposição para o caso das emoções-próprias, substratos mais imediatos dos sentimentos. Segundo o esquema damasiano, a primeira fase de uma emoção ou reação emocional é a apreciação, avaliação ou estimativa (appraisal, ${ }^{4}$ no original) por parte de um organismo do que ele chama de um "estímulo emocionalmente competente" (emotionally competent stimulus). Imaginemos um organismo humano em equilíbrio homeostático em certo intervalo de tempo. Nenhuma emoção-própria particular domina seu corpo nesse momento. Eis que um estímulo ou objeto emocionalmente competente invade seu campo perceptivo. Esse indivíduo então (seu aparato perceptual-cognitivo, órgãos e córtices sensórios cerebrais mais precisamente) identifica, isola, acessa tal objeto:

Em termos neurais, imagens relacionadas ao objeto emocionalmente competente devem ser representadas em um ou mais dos sistemas de processamento sensório do cérebro, tais como as regiões visuais ou auditivas. Vamos chamar isto de estágio de presentificação (presentation stage) do processo. Não importa quão efêmera a presentificação, sinais relacionados à presença daquele estímulo são disponibilizados a um número de sítios disparadores

de emoção em outros locais do cérebro. Podemos conceber esses sítios como cadeados que apenas podem ser abertos se as chaves apropriadas se encaixarem. Os estímulos emocionalmente competentes são as chaves, é claro. Notem que elas selecionam um cadeado preexistente, em vez de instruir o cérebro sobre como criar um. Os sítios de disparo emocional subseqüentemente ativam um número de sítios de execução emocional em outras partes do cérebro. Esses últimos são a causa imediata do estado emocional que ocorre nas regiões do corpo e do cérebro que sustentam o processo emotivo-sentimental (Damásio 2003: p.p. 57-8, grifos meus).

A sequência então é: avaliação ou percepção de um estímulo emocionalmente competente; presentificação ou representação do estímulo

4 Tenho dificuldade de aceitar a expressão que Damásio utiliza como ponto de partida do processo emocional: appraisal. Appraisal significa avaliação, apreciação, estimativa. Como o processo que vai dar em uma emoção pode começar já por uma avaliação? A avaliação não seria o resultado final do processo? É verdade que o autor afirma que pode haver um appraisal na ausência de percepção consciente; neste caso, appraisal pode ser pensado como sinônimo de assessing, perception. Para que a idéia fique coerente para mim, prefiro pensar nesse appraisal não consciente como sinônimo de isolamento ou delimitação de um sinal ou estímulo. 
nos córtices sensoriais; ativação de sítios disparadores emocionais; ativação de sítios de execução emocional; mudanças no meio interno, nas vísceras, no sistema músculo-esquelético, no processamento mental e em outros comportamentos específicos. Esse seria o percurso clássico na base dos estados emocionais. Como veremos adiante, as alterações orgânicas podem ser simuladas em nível cerebral, dispensando uma ou mais fases do processo. Estas se mostraram consistentemente relacionadas à ativação de diferentes estruturas cerebrais.

\begin{tabular}{ll}
\hline \multicolumn{1}{c}{ Fases da reação emocional } & \multicolumn{1}{c}{ Sítios cerebrais envolvidos } \\
\hline $\begin{array}{l}\text { Avaliação (appraisal) e presentificação de } \\
\text { um estímulo emocionalmente } \\
\text { competente }\end{array}$ & $\begin{array}{l}\text { Córtices cerebrais de associação sensória } \\
\text { e de ordem superior }\end{array}$ \\
Disparo emocional & $\begin{array}{l}\text { Amígdala, no fundo do lobo temporal, } \\
\text { uma parte do lobo frontal conhecida como } \\
\text { córtex pré-frontal ventromedial, e ainda } \\
\text { uma outra região frontal na área motora } \\
\text { suplementar e cingulada. }\end{array}$ \\
& $\begin{array}{l}\text { Hipotálamo, o prosencéfalo basal e alguns } \\
\text { núcleos no tegmento do tronco cerebral. }\end{array}$ \\
Execução emocional & $\begin{array}{l}\text { Mudanças no meio interno, nas vísceras, } \\
\text { no sistema músculo-esquelético e no } \\
\text { processamento mental }\end{array}$ \\
\hline
\end{tabular}

De particular interesse para a elaboração de minha hipótese para o fenômeno da flash aesthesis é a passagem citada acima, que dá conta da relação entre a representação ou presentificação cerebral do estímulo emocionalmente competente e a ativação de determinado padrão de disparo emocional. Damásio utiliza a imagem da chave e fechadura/cadeado. Chaves (objetos ou estímulos) diferentes abrem (ativam) diferentes fechaduras (padrões de disparo emocional). Mais adiante, ao apresentar o mecanismo das zonas de convergência e dos registros neurais dispositivos, explorarei mais o assunto. Antes finalmente de avançar sobre a caracterização dos sentimentos, um resumo da hipótese-definição de Damásio da emoção:

Uma emoção-própria, tal como felicidade, tristeza, embaraço, simpatia, é uma coleção complexa de respostas químicas e neurais formando um padrão distintivo. As respostas são produzidas pelo cérebro normal quando este detecta um estímulo emocionalmente competente (EEC), o objeto ou situação em cuja presença, real ou evocada mentalmente, dispara a emoção. As respostas

são automáticas. $O$ cérebro é preparado pela evolução para responder a certos 
EEC com um repertório específico de ações. No entanto, a lista de EEC não está confinada àqueles prescritos pela evolução. Muitos outros são aprendidos pela experiência. O resultado imediato destas respostas é uma mudança temporária no estado do corpo próprio (body proper) e no estado das estruturas cerebrais que mapeiam o corpo e sustentam o pensamento. O resultado último dessas respostas, direta ou indiretamente, é a colocação do organismo em circunstâncias que conduzam à sobrevivência e ao bem-estar (Damásio 2003: 53, grifo meu).

Fase distinta do mesmo processo, o sentimento é a percepção de todas as etapas anteriores. Assumindo tratar-se de uma estratégia metodológica Damásio reserva o termo sentimento para a expressão mental das modificações neuroquímicas que constituem uma emoção, tal como mapeadas em regiões específicas do cérebro. ${ }^{5}$ Igualmente objeto de discussão em seus três livros, muitas são também as definições sugeridas para o fenômeno do sentimento. "A essência de um sentimento (o processo de viver uma emoção) não é uma qualidade mental ilusória associada a um objeto, mas sim a percepção direta de uma paisagem específica: a paisagem do corpo" (Damásio 1996: 14); “... os sentimentos são tão cognitivos como qualquer outra imagem perceptual e tão dependentes do córtex cerebral como qualquer outra imagem" (Damásio 1996: 190); sentimentos são as percepções de nossas emoções; referemse a alguma variante da experiência de dor ou prazer como esta ocorre em emoções e fenômenos relacionados; são sempre escondidos, como todas as imagens mentais necessariamente são, invisíveis a qualquer um que não seja o seu próprio possuidor; representam a propriedade mais privada do organismo em cujo cérebro eles ocorrem; compõem o teatro da mente; ocorrem quando mudanças alcançam um limite crítico no mapeamento cerebral dos estados do corpo; são componentes fundacionais de nossas mentes; são a idéia do corpo sendo de um certo modo; emergem de qualquer conjunto de reações homeostáticas, não apenas

5 A pesquisa aqui avançada partilha com Damásio e com uma corrente teórica denominada por Alfredo Pereira Júnior (1997: 147-8) de monismo estratificado, a concepção de que mente e corpo constituem a mesma substância ou realidade, sendo porém fenômenos distintos, paralelos ou coocorrentes. Um sentimento é uma imagem mental sustentada por um complexo de interações eletroquímicas, mas não é reduzível a este. Vale lembrar aqui também a famosa lacuna explanatória reconhecida pela maior parte dos cientistas cognitivos. Sabe-se que a experiência subjetiva, a consciência, etc. são fenômenos consistentemente relacionados com processos neurofisiológicos, mas ninguém ainda foi capaz de apresentar uma explicação razoável para como exatamente um padrão neural torna-se uma imagem mental. Desse modo, a investigação dos sentimentos padece das mesmas dificuldades e limitações enfrentadas pelos estudos da formação de diferentes imagens mentais (palavras, pensamentos, imagens, cheiros, sons, sabores, texturas, etc.) como são experimentadas na perspectiva de primeira pessoa. Nem por isso o atual estágio de conhecimento desses processos deixa de ser extremamente verossímil, útil e revelador. 
a partir de emoções-próprias; traduzem o curso do estado da vida na linguagem da mente; resultam da percepção de um certo estado do corpo juntamente com a percepção de um certo modo de pensar e de pensamentos com certos temas (Damásio 2003).

Convém reforçar que para Damásio todos esses processos que vão desde as regulações metabólicas (presentes também em organismos sem sistema nervoso e sem vida mental) até os sentimentos, visam cada um em seu nível à manutenção da vida com vistas à sobrevivência e ao bem-estar. Nesse sentido é razoável afirmar que o sentimento tenha surgido mais tarde evolutivamente quando o volume e característica dos estímulos emocionalmente competentes a serem analisados excederam a capacidade de processamento do corpo biológico inconsciente, exigindo a intervenção de uma mente consciente.

Mapas do estado do corpo provêm uma assistência limitada sem sentimentos conscientes. Os mapas funcionam para problemas de certos graus de complexidade e não mais; quando o problema se torna muito complicado quando requer a mistura de respostas automáticas e raciocínio sobre conhecimento acumulado mapas inconscientes não mais ajudam e os sentimentos vêm à mão. (...) Apenas o "nível mental" das operações biológicas permite a integração temporal de grandes conjuntos de informações necessária para os processos de solução de problemas. (...) Os sentimentos rotulam os mapas neurais relacionados com um selo que diz: "Marque isso!" (Damásio 2033: 176-8).

Assim como para as etapas anteriores, Damásio e colaboradores, além de outros pesquisadores independentes, constataram que a evocação ou emergência de sentimentos está necessariamente vinculada com a atividade de certas regiões cerebrais específicas, a saber: o córtex cingulado, dois dos córtices somatossensoriais (conhecidos como ínsula e S2), o hipotálamo e vários núcleos no tegmento do tronco cerebral (a parte posterior do tronco cerebral). Essas são exatamente as áreas cerebrais responsáveis pelo mapeamento dos sinais corporais, o que corrobora a tese damasiana de que sentir uma emoção está de fato associado a mudanças no mapeamento neural dos estados do corpo.

Só que nem sempre é assim. "Sentimentos não emergem necessariamente a partir dos estados do corpo reais embora isso possa acontecer mas, ao contrário, a partir dos mapas reais construídos a qualquer momento nas regiões sensório-corporais" (Damásio 2003: 112). Já em o "Erro de Descartes", Damásio (1996) sugeria que em inúmeros momentos o cérebro aprende a forjar uma imagem simulada de um estado emocional do corpo sem ter de a reconstruir no corpo propriamente dito. Segundo o autor, existem mecanismos neurais que nos ajudam a sentir 
"como se" estivéssemos passando por um estado emocional, "como se" o corpo estivesse sendo ativado e alterado. Trata-se de um mecanismo alternativo de produção de sentimentos que não envolve necessariamente o mapeamento dos estados do corpo atuais em determinado momento. A este mecanismo Damásio dá o nome de "alça corpórea virtual" (as-if-body-loop mechanism).

Desse modo, uma emoção pode ser sentida não graças às modificações causadas no corpo pelos sítios de execução emocional, mas sim à função de sinais transmitidos diretamente do córtex pré-frontal para as regiões de sensoriamento corporal. Esse mecanismo estaria por trás, por exemplo, do que chamamos de empatia. A capacidade que temos de simular em nós os sentimentos experimentados por outros.

O resultado da simulação direta dos estados do corpo nas regiões cerebrais de sensoriamento não é diferente daquele de filtragem dos sinais provenientes do corpo. Em ambos os casos o cérebro momentaneamente cria um conjunto de mapas corporais que não corresponde exatamente à realidade corrente do corpo. O cérebro usa os sinais corporais como barro para esculpir um estado corporal particular nas regiões onde tais padrões podem ser construídos, isto é, as regiões cerebrais de sensoriamento corporal (Damásio 2003: 116).

Mais adiante, quando apresentar a idéia dos padrões neurais dispositivos, ficará um pouco mais claro o modo pelo qual o organismo desenvolve essa capacidade de simulação. Antes, porém, cabe desenvolver um pouco melhor o aspecto propriamente cognitivo dos sentimentos. Tal como caracterizado em uma das definições, um sentimento é o resultado da percepção de um certo estado do corpo juntamente com a percepção de um certo modo de pensar e de pensamentos com certos temas. Além de constituído do mapeamento dos estados do corpo reais ou simulados, um sentimento é também composto pelo ritmo e conteúdo dos pensamentos que acompanham aqueles estados. Difícil apontar o que é causa e o que é efeito, mas o fato é que em geral o bom funcionamento do corpo (meio interno, vísceras, etc) é acompanhado por pensamentos positivos e numerosos, enquanto o funcionamento precário ou patológico do corpo é acompanhado por pensamentos negativos e repetitivos ${ }^{6}$. Presentificado no ambiente cerebral, um pensamento, uma idéia, um conteúdo men-

6 Nós sustentamos imagens de nosso próprio estilo de pensar. No caso de sentimentos positivos a mente representa bem estar e também bem pensar. Por outro lado, "sentir-se triste não se refere apenas a uma doença corporal ou a contínua falta de energia. Freqüentemente está relacionado a um modo de pensar ineficiente restrito a um limitado número de idéias de perda" (Damásio 2003: 89). 
tal funciona como um novo estímulo emocionalmente competente que através de outros circuitos neurais modifica o padrão distintivo de funcionamento dos mapas nas regiões somatossensoriais.

Esse processo de acompanhamento contínuo, essa experiência do que o corpo está fazendo enquanto pensamentos sobre conteúdos específicos continuam a desenrolar-se, é a essência daquilo que chamo de um sentimento. Se uma emoção é o conjunto das alterações no estado do corpo associadas a certas imagens mentais que ativaram um sistema cerebral específico, a essência do sentir uma emoção é a experiência dessas alterações em justaposição com as imagens mentais que iniciaram o ciclo. Em outras palavras, um sentimento depende da justaposição de uma imagem do corpo propriamente dito com uma imagem de alguma outra coisa, tal como a imagem visual de um rosto ou a imagem auditiva de uma melodia. O substrato de um sentimento completa-se com as alterações nos processos cognitivos que são induzidas simultaneamente por substâncias neuroquímicas (por exemplo, pelos neurotransmissores numa série de pontos neurais, em resultado da ativação dos núcleos neurotransmissores que faziam parte da resposta emocional inicial) (Damásio 1996: 175).

Quando nos sentimos bem surgem pelo menos duas consequências: o aparecimento de pensamentos com temas consoantes com o sentimento e um modo de pensar, um estilo de processamento mental que aumenta a velocidade de geração das imagens e que as torna mais abundantes. Estados emocionais percebidos como felizes, agradáveis ou gratificantes envolvem ou dão lugar a uma dinâmica de processamento mental caracterizada pela abundância de imagens e por sua mais rápida geração. Além disso, o sentimento de alegria induz à ocorrência de pensamentos alegres. Sentimentos, portanto e mais uma vez, envolvem a percepção de um certo estado do corpo e a percepção de um certo estado da mente. As mudanças no modo de pensar são conseqüências e causas dos sentimentos. À medida que em paralelo às imagens do corpo nós sustentamos imagens de nosso próprio estilo, eficiência e conteúdo do pensar em nossos sentimentos vão se modulando, intensificando ou arrefecendo.

Um caso curioso citado por Damásio (2003: 65-73) para ilustrar a íntima relação e coerência entre emoções, sentimentos e pensamentos, é o de uma senhora acometida do mal de Parkinson. Constatando que a paciente não respondia ao tratamento neuroquímico tradicional, os médicos que a assistiam resolveram testar uma abordagem alternativa. $\mathrm{O}$ mal de Parkinson é uma doença que se caracteriza pelo enrijecimento dos músculos, tremores e dificuldade de iniciar os movimentos. Apesar de se tratar de uma doença incurável, a maior parte dos parkinsonianos 
responde bem à administração de medicamentos contendo levodopa, substância projetada para aumentar o nível de dopamina no organismo. No entanto, para aqueles que não reagem ao tratamento químico, outras soluções foram desenvolvidas, entre elas a que consiste no implante de minúsculos eletrodos no tronco cerebral do paciente, de tal modo que a passagem de uma corrente elétrica de baixa intensidade e alta freqüência possa mudar o modo como certos núcleos motores operam. O resultado em geral é excelente. Os pacientes passam a poder mover suas mãos com precisão e a andar normalmente. O posicionamento preciso do feixe de eletrodos é fundamental para o sucesso do tratamento.

Para grande surpresa da equipe médica responsável pela aplicação do procedimento na senhora citada, a qual não apresentava nenhum histórico de depressão ou desordem psiquiátrica, a passagem de corrente elétrica em um dos quatro locais de contato do lado esquerdo do tronco cerebral da paciente, dois milímetros abaixo daquele que melhorava sua condição, provocou um espantoso conjunto de reações inesperadas. A paciente parou abruptamente a conversa que mantinha, baixou os olhos e seu rosto foi tomado por uma expressão de profunda tristeza. Alguns segundos depois começou repentinamente a chorar e logo estava soluçando. Passou então a falar quão profundamente triste se sentia, que não tinha energias para viver mais daquele modo, que estava desesperada, exausta e preferia morrer a continuar se sentindo assim.

Percebendo que o deplorável estado da paciente era devido à corrente elétrica induzida, o médico responsável abortou o procedimento. Noventa segundos depois o comportamento da senhora voltou ao normal. O choro, a tristeza e as afirmações angustiadas desapareceram tão abruptamente quanto surgiram. Rapidamente voltou a sorrir e a mostrar-se relaxada. "O que foi tudo isso?", perguntou. Ela havia se sentido péssima, mas não sabia por quê. A equipe que a assistia também não tinha certeza, mas o mais provável é que a corrente elétrica em vez de passar pelas estruturas gerais de controle motor, havia seguido por um dos núcleos do tronco cerebral que controlam certos tipos particulares de ação. Essas ações (movimentos da musculatura facial, movimentos da boca, laringe, faringe, diafragma e várias ações que resultam na produção e eliminação de lágrimas) em conjunto produzem a emoção de tristeza. Tudo se passa como se um estímulo emocionalmente competente tivesse sido percebido na mente da paciente e instaurado todas aquelas reações corporais. Ao contrário, o processo foi tipicamente de "baixo para cima". A ativação de determinado padrão de disparo em uma região cerebral específica causou uma série de respostas motoras, 
que por sua vez modificaram o mapa somatossensório fazendo emergir o sentimento de tristeza e com ele uma série de pensamentos negativos.

A seqüência de eventos no paciente revela que a emoção tristeza vem primeiro. O sentimento tristeza em seguida, acompanhado por pensamentos do tipo que normalmente podem causar e então acompanhar a emoção tristeza, pensamentos que são característicos de estados da mente que coloquialmente descrevemos como "sentir-se triste", "estar mal". Uma vez eliminado o estímulo essas manifestações cessam e desaparecem. A emoção é suprimida, assim como o sentimento. Os pensamentos problemáticos desaparecem também. Em condições normais, a velocidade com a qual emoções emergem e dão lugar a sentimentos e pensamentos relacionados torna difícil analisar a seqüência real do fenômeno. Como pensamentos, normalmente causadores de emoções, aparecem na mente, eles causam emoções que dão lugar a sentimentos que evocam outros pensamentos que são tematicamente relacionados e provavelmente amplificam a reação emocional (Damásio 2003: 70).

Apesar de se tratar de um caso isolado, uma exceção no histórico do tratamento do mal de Parkinson por estimulação elétrica, e portanto de valor científico limitado, o fenômeno observado na senhora citada pode ser considerado de grande valor na corroboração da hipótese de que os processos da emoção e do sentimento podem ser analisados por componentes. Além disso, reafirma uma noção fundamental em neurociência cognitiva: "Toda função mental complexa resulta da contribuição orquestrada de muitas regiões cerebrais em vários níveis do sistema nervoso central, em vez de ser o resultado do trabalho de uma única região cerebral concebida à maneira frenológica" (Damásio 2003: 73).

Acreditando ter esclarecido, ainda que sumariamente, as noções de emoção e sentimento sugeridas por Damásio, e aqui defendidas com o objetivo de compreender o fenômeno da flash aesthesis, passo agora para que em seguida retome o desenvolvimento da hipótese para a pergunta de como e por que um corpo a cria para si - a expor os mecanismos através dos quais a presentificação de determinado objeto ou estímulo emocionalmente competente aciona um conjunto específico de reações e não outro.

\section{Zonas de convergências, marcadores somáticos, padrões neurais dispositivos}

Antes de mais nada convém ressaltar a distinção entre respostas inatas (filogenéticas) e respostas elaboradas ou ambientais (ontogené- 
ticas). Como observado anteriormente, a lista de estímulos ou objetos capazes de provocar certos padrões distintivos de reação emocional não tem caráter estático e inclui desde aqueles capazes de ativar automatismos geneticamente programados (os quais também podem ser mais ou menos modificados pela experiência e pelo autocontrole) até aqueles em constante mutação, influenciados pela cultura, pela moda e até mesmo pelo momento, fase ou etapa particular da vida na qual os encontramos. No caso da pequena experiência estética imediata, breve experiência estética automática, estetização instantânea ou flash aesthesis, a lista de objetos ou estímulos capazes de fazê-la emergir muda constantemente no decorrer de uma vida. É muito provável, ainda que eu não tenha me aprofundado sobre isso, que nosso gosto, nossas preferências estéticas se desenvolvam a partir de certos valores sensórioperceptivos inatos. Ao nascermos, ou nos primeiros meses de vida, já possuímos sistemas cerebrais que induzem respostas mais ou menos gratificantes para o organismo função da percepção deste ou daquele objeto ou estímulo. ${ }^{7}$ É possível que toda a nossa sensibilidade seja influenciada por essas condições iniciais.

Ora, inatas ou adquiridas, o fato é que certas estruturas cerebrais, no aqui e agora de uma percepção sensível, comandam a emergência de uma experiência de intensidade invulgar. O que são elas, como operam? Ainda acompanhando o referencial damasiano, a idéia geral aqui é a de que a presentificação ou representação mental momentânea, em um córtice sensório específico, de determinado objeto percebido ocasiona, imediata e instantaneamente (algo da ordem dos milesegundos), o disparo de padrões específicos de ativação neuronal em vários outros sítios cerebrais tais como a amígdala, o córtex pré-frontal ventromedial, o hipotálamo, a insula, etc., dando lugar a emoções, sentimentos e pensamentos igualmente específicos. Há pelo menos duas coisas ou etapas a destacar aqui. Uma é entender de que maneira o cérebro associa certa representação mental a determinado conjunto de comandos de ativação, ou seja, como e por que imagens percebidas, sentimentos e pensamentos se associam e ganham estabilidade em uma espécie de pacote neural. A outra é compreender como uma associação já mais ou menos estabilizada é ativada e cumpre sua função. ${ }^{8}$

7 Rhodes et al. (2002), Bednar and Miikkulainen (2000).

8 Este parece ser mais um caso do dilema clássico entre o ovo e a galinha. O que vem primeiro: uma associação estável entre percepção e sentimento do tipo "se isso então aquilo", ou a avaliação não-condicionada de um estímulo concomitante ao mapeamento dos estados do corpo com asso- 
Um dos mecanismos por trás do primeiro processo é o chamado marcador somático. Toda imagem mental - seja um pensamento, um trecho musical ou um cheiro - é em geral simultaneamente acompanhada por outra imagem mental, qual seja, um sentimento, a imagem do corpo real ou simulado tal como mapeado nos córtices somatossensórios. O mecanismo do marcador somático recebe esse nome porque mudanças no ambiente interno do corpo (soma) são usados para marcar percepções e informações sensórias vindas do ambiente externo. Temporalmente justapostos à percepção ou recordação de algo, os sentimentos acabam por se tornar "qualificadores" dessa coisa que é percebida ou recordada. Dado que padrões neurais co-ocorrentes em um determinado momento tendem a reaparecer em conjunto quando um deles é presentificado, podemos dizer que o sentimento funciona como um marcador somático das outras imagens mentais. O estado corporal associado a uma imagem mental marca essa mesma imagem com um valor positivo ou negativo. Damásio desenvolve a hipótese do marcador somático ao estudar o mecanismo de tomada de decisão, mas avalia que se trata de uma estratégia evolutiva bastante útil nos casos mais variados.

Os marcadores-somáticos são adquiridos por meio da experiência, sob o controle de um sistema interno de preferências e sob a influência de um conjunto externo de circunstâncias. (...) A base neural para o sistema interno de preferências consiste, sobretudo, em disposições reguladoras inatas com o fim de garantir a sobrevivência do organismo. Conseguir sobreviver coincide com conseguir reduzir os estados desagradáveis do corpo e atingir estados homeostáticos, isto é, estados biológicos funcionalmente equilibrados. O sistema interno de preferências encontra-se inerentemente predisposto a evitar a dor e a procurar o prazer (Damásio 1996: 211).

Aplicada especificamente à compreensão do processo de tomada de decisão, a hipótese do marcador somático explicita o fundamento biologico no qual nos baseamos ao selecionarmos uma opção de ação entre várias possíveis. Ações anteriores que acarretaram um estado emocional desagradável, assim ficam marcadas. Quando ressurge a

ciação posterior entre ambos? O mais provável é que ambas as coisas aconteçam. Não nascemos tábula rasa e podemos mudar consideravelmente nossas reações pré-programadas graças à educação e aos estímulos que recebemos. A constatação de preferências estéticas em recém-nascidos evidencia a presença de predisposições inatas. Os padrões neurais dispositivos sobre os quais falarei em seguida já estão presentes ao nascermos, mas evidentemente são modificados pela experiência, pelo aprendizado, pelo ambiente e pela cultura com o auxílio dos marcadores somáticos. 
imagem mental associada a uma dada opção de resposta, por mais fugaz que seja, sentimos uma sensação visceral incômoda. O marcador somático faz convergir a atenção para o resultado negativo a que a ação pode conduzir e atua como um sinal de alarme automático que diz: atenção ao perigo decorrente de escolher a ação que terá esse resultado. Suspeito que o processo educativo é em boa medida apoiado em mecanismos desse tipo. Falamos um palavrão e recebemos um tapa na boca. Da próxima vez que estamos para falar um palavrão em circunstâncias semelhantes, a sensação de dor retorna e pensamos duas vezes. Em outros casos, os pais nem precisam chegar às vias de fato, bastando a elevação da voz ou uma expressão facial mais séria para que o recado seja dado.

Mas de que forma exatamente a percepção do corpo atribui um valor ou anexa sua valência a determinado estado mental? Que sítios e circuitos cerebrais estão envolvidos no processo? Segundo Damásio, o sistema neural crítico para a aquisição da sinalização pelos marcadoressomáticos, no caso do raciocínio lógico, situa-se principalmente nos córtices pré-frontais, onde é, em grande parte, coextensivo com o sistema das emoções próprias. Os córtices pré-frontais contêm algumas das poucas regiões cerebrais com acesso aos sinais sobre praticamente toda a atividade que ocorre em qualquer "ponto" da mente e do corpo. As preferências inatas do organismo relacionadas com a sua sobrevivência o sistema de valores biológicos, por assim dizer são transmitidas aos córtices pré-frontais por meio desses sinais, fazendo desse modo parte integrante do mecanismo de tomadas de decisões.

Avalio que o mesmo ocorra no processo de configuração de predisposições, aversões e preferências pessoais. Nesse caso, as regiões aptas a reunir os sinais corporais, ou sua simulação virtual aos outros estados mentais se multiplicam, e incluem desde os córtices temporais e frontais de ordem superior até núcleos subcorticais como os da amígdala. Aparece aqui, na transição entre as duas etapas a que me referi anteriormente, a idéia das zonas de convergência. Estas são constituídas por pequenos grupos de neurônios localizados em variados córtices e núcleos subcorticais que reúnem os sinais do processamento cognitivo, dos órgãos sensórios e dos estados do corpo ocorridos simultaneamente. As zonas de convergência registram a associação de categorias específicas de estímulos a categorias específicas de estados somáticos. Elas constituem o repositório dos registros das contingências categorizadas de nossa experiência de vida. Conforme Damásio, nesses pequenos aglomerados de neurônios e sinapses forma-se uma tendência ou 
predisposição de disparo emocional-cognitivo. Um marcador somático ou outro mecanismo qualquer (uma instrução genética ou uma nova informação, por exemplo) cria em uma zona de convergência, localizada em algum sítio cerebral, um registro dispositivo ou padrão neural dispositivo. As disposições estão contidas em conjuntos de neurônios denominados zonas de convergência.

Utilizando a expressão "representação" que desapareceria nos livros posteriores e que acredito poder ser substituída por registro ou mesmo padrão neural, Damásio afirma:

As representações dispositivas constituem o nosso depósito integral de saber e incluem tanto o conhecimento inato como o adquirido por meio da experiência. O conhecimento inato baseia-se em representações dispositivas existentes no hipotálamo, no tronco cerebral e no sistema límbico. Podemos concebê-los como comandos da regulação biológica necessários para a sobrevivência (isto é, o controle do metabolismo, impulsos e instintos). O conhecimento adquirido baseia-se em representações dispositivas existentes tanto nos córtices de alto nível como ao longo de muitos núcleos de massa cinzenta localizados abaixo do nível do córtex. A aquisição de conhecimento novo é conseguida pela modificação contínua dessas representações dispositivas. Quando as representações dispositivas são ativadas, elas podem dar origem a vários resultados. Podem disparar outras representações dispositivas, com as quais estão fortemente relacionadas pelo design do circuito (...) ou podem gerar uma representação topograficamente organizada para os córtices sensoriais primários ou podem ainda gerar um movimento pela ativação de um córtex motor ou de um núcleo, como por exemplo os gânglios basais (1996: 132-3).

Damásio usa o termo "dispositivos" porque o que eles fazem é dar ordens a outros padrões neurais, tornar possível que a atividade neural ocorra em outro local, em circuitos que fazem parte do mesmo sistema e com os quais se estabeleceu uma forte interconexão neuronal. Um registro ou padrão neural dispositivo é uma potencialidade de disparo dormente que ganha vida quando os neurônios se acionam com um determinado padrão, a um determinado ritmo, num determinado intervalo de tempo e em direção a um alvo particular, que é outro conjunto de neurônios. As representações ou registros dispositivos existem como padrões potenciais de atividade neuronal nos pequenos grupos de neurônios constituintes das chamadas zonas de convergência. Quando circuitos dispositivos são ativados, sinalizam para outros circuitos e fazem com que imagens ou ações sejam geradas de outras partes do cérebro. 


\section{Espaços de imagem, espaços dispositivos, registro de registros dispositivos}

Multiplicando os termos, Damásio fala ainda em dois tipos de espaços: o espaço de imagem e o espaço dispositivo. O espaço de imagem é aquele no qual imagens de todos os tipos sensoriais ocorrem explicitamente. Essas imagens constituem nossos estados mentais conscientes, são as imagens que experimentamos por percepção direta ou evocação. "O espaço dispositivo é aquele que contém as disposições formadoras da base de conhecimentos e dos mecanismos que permitem construir imagens por evocação, gerar movimentos e facilitar o processamento de imagens" (Damásio 2000: 418). Os conteúdos do espaço de imagem são explícitos e podemos conhecê-los. Ao contrário, os conteúdos do espaço dispositivo são implícitos e nunca os conhecemos diretamente. Os conteúdos das disposições são sempre inconscientes e existem de forma dormente ou potencial. São eles, no entanto, que produzem reações como liberação de hormônios e neurotransmissores, contração ou extensão de músculos, arrepios, sensação de bem-estar, rubor, lembrança de experiências passadas etc.

Toda a nossa memória, herdada da evolução e disponível ao nascermos ou adquirida desde então pelo aprendizado em suma, toda a nossa memória sobre coisas, propriedades das coisas, pessoas e lugares, eventos e relações, habilidades, regulações biológicas, tudo, existe na forma dispositiva (ou seja, implícita, oculta, inconsciente), aguardando para tornar-se uma imagem explícita ou uma ação. As disposições não são palavras. São registros abstratos de potencialidades (Damásio 2000: 419).

Damásio alerta para o fato de que estamos apenas começando a desvendar os sítios e circuitos que sustentam ambos os espaços, mas algumas evidências já permitem conclusões preliminares. Os padrões neurais explícitos do espaço de imagem são alicerçados pelos córtices sensoriais iniciais das várias modalidades sensórias, assim como por algumas partes das áreas límbicas como os córtices do cíngulo e por estruturas subcorticais como o teto do mesencéfalo. Por outro lado, os espaços dispositivos ou registros implícitos de conhecimento estão contidos nos córtices de ordem superior, em partes dos córtices límbicos e em numerosos núcleos subcorticais, da amígdala ao tronco cerebral. Isso sem citar outras áreas cerebrais responsáveis pela transmissão e controle de sinais entre as várias regiões do cérebro. 
À divisão entre um espaço de imagem e um espaço dispositivo corresponde uma divisão em 1) mapas de padrões neurais explícitos ativados em córtices sensoriais iniciais, nos chamados córtices límbicos e em alguns núcleos subcorticais e 2) zonas de convergência, localizadas em córtices de ordem superior e em alguns núcleos subcorticais (Damásio 2000: 422).

E isso ainda não é tudo. Damásio esclarece mais um ponto relacionado às estruturas dispositivas de grande relevância para a hipótese que apresentarei em seguida. Segundo o autor, nossas memórias conceituais, autobiográficas e, sugiro eu, estéticas, são distribuídas em várias regiões diferentes e descontínuas ao longo do cérebro. O que sabemos sobre determinado objeto ou vivência não fica armazenado em um único local, mas sim em sítios neurais separados. Damásio dá o exemplo de um martelo. Os diferentes aspectos de nossa interação passada com martelos sua forma, o modo de usar, a expressão que o nomeia, sua função, etc. são registros dormentes, dispositivos e implícitos, cada um deles localizado em diferentes córtices de ordem superior. Sítios cerebrais capazes de armazenar imagens visuais não são os mesmos que armazenam palavras, assim como não coincidem as áreas que memorizam padrões táteis e de movimento.

A separação espacial não se revela um problema, pois, quando todos os registros são tornados explícitos em forma de imagem, eles são exibidos em apenas alguns sítios e coordenados no tempo de tal modo que todos os componentes registrados parecem integrados sem solução de continuidade. Se eu disser a palavra martelo e perguntar a você o que significa "martelo", você me dará uma definição viável desse instrumento e com presteza. Uma base para essa definição é a rápida mobilização de vários padrões mentais explícitos relativos a esses aspectos variados. Embora a memória de aspectos separados de nossa interação com martelos seja mantida no modo dormente, em partes separadas do cérebro, essas diferentes partes são coordenadas no âmbito de seus circuitos, de modo que os registros dormentes e implícitos possam ser transformados, rapidamente e em estreita proximidade temporal, em imagens explícitas, ainda que apenas esboçadas (Damásio 2000: 282-3).

Damásio não é muito claro quanto a isso, mas me parece razoável imaginar que exista algo como um registro de registros dispositivos ou um espaço de espaços dispositivos que armazena, reúne, concentra em sua comunidade de neurônios as instruções ou comandos de sinalização necessários para que registros ou espaços dispositivos associados, localizados em outras partes, "acordem" e dêem lugar à emergência or- 
questrada de imagens mentais das mais variadas espécies. Arrisco-me a propor adicionalmente que um espaço de espaços dispositivos ou um super-espaço dispositivo, vale dizer, um padrão de padrões neurais dormente, potencial localizado em uma zona de convergência, é formado a partir da integração sincrônica dos inúmeros sinais emitidos pelo processamento atual de uma percepção complexa operada nos variados córtices sensórios. ${ }^{9}$

Em outras palavras, ao vivenciarmos uma experiência, diferentes regiões do cérebro são ativadas, tantas quantas forem as modalidades sensórias envolvidas na mesma. Assim, no córtex visual forma-se um padrão neural correspondente à imagem percebida, no córtex olfativo forma-se um padrão neural correspondente ao cheiro percebido, no córtex somatossensório forma-se um padrão neural correspondente ao sentimento experimentado naquele momento, etc. No intervalo de tempo da vivência tudo é percebido como um todo integrado e coerente. Não sendo capaz, no entanto, de armazenar em um único local tudo o que está associado àquela experiência, o organismo cria em uma zona de convergência um espaço dispositivo que resulta da sinalização sincrônica e convergente desses variados padrões neurais simultâneos. Mais tarde, quando por alguma razão mostrar-se necessário retomar os diversos aspectos relacionados com uma dada vivência (experiência, lembrança, pensamento, sentimento), o registro dispositivo funcionará como um disparador multidirecional, facilitador da reativação dos vários padrões neurais, nos diferentes córtices sensórios e núcleos límbicos associados.

Vale notar ainda que os padrões neurais atuais correspondentes ao espaço de imagem são também posteriormente armazenados na forma de registros dispositivos. Quando queremos evocar o perfume que sentimos em uma dada ocasião, o padrão neural dispositivo criado a partir da percepção real do mesmo é ativado e podemos como que senti-lo novamente ainda que com menor intensidade. É relacionado a isso que dizemos que um registro dispositivo pode tanto ativar outro registro dispositivo, quanto pode gerar uma representação topograficamente organizada (uma imagem visual, por exemplo) ou ainda disparar um movimento, etc. De acordo com minha sugestão, um super-registro dispositivo seria um ativador de outros registros dispositivos enquanto es-

9 Essa "integração sincrônica" é também investigada sob a denominação de "binding problem". Tal como entendo, o processo de integração das variadas funções cerebrais, facilitado pelo mecanismo da consciência, é parte fundamental da explicação para a formação de hiper-registros dispositivos. 
tes últimos dariam lugar a coisas não-dispositivas como imagens, ações, liberação de neurotransmissores, etc. O processo não terminaria aí, no entanto. Cada um dos resultados da ativação dos registros dispositivos seria novamente sinalizado em outros espaços dispositivos, dando continuidade ao processo.

Como disse logo acima, Damásio não me parece claro quanto ao mecanismo responsável pela ativação rápida, eficaz e sincronizada dos registros implícitos associados a uma experiência. O autor limita-se a afirmar que esses registros são estreitamente coordenados por conexões neurais de modo que seus conteúdos possam ser evocados e tornados explícitos. Uma rede reativada baseada em zonas de convergência. A idéia de um padrão de padrões neurais dispositivos coordenando o processo parece-me razoável e coerente com o exposto até o momento. ${ }^{10}$

\section{Presentificação, Emergência do Hiper-Espaço Dispositivo, Execução Afetivo-Cognitiva, Flash Aesthesis - um modelo neurofilosófico para a experiência estética}

Esses, em resumo, os dados apresentados por Damásio. Passo agora a mostrar como podem ajudar a compreender o acontecimento de uma estetização instantânea. A proposição que farei em seguida reunirá, disporá em diálogo conceitos-estruturas não relacionados pelo autor. As "idéias" dispositivas não aparecem em seu último livro. Porém sua explicação das reações emocionais em etapas de presentificação, disparo e execução são claramente um exemplo daquelas. Farei também várias suposições e apostas. Algumas delas talvez já sejam evidências estáveis na ciência neural das quais ainda não tomei conhecimento. Uma argumentação mais precisa e abrangente exigirá estudos e investigações adicionais. Além disso, não me aventurarei (não estou capacitado para tanto e nem mesmo a neurociência atual está) no estabelecimento preciso dos circuitos, sítios e percursos cerebrais envolvidos no acontecimento de um lampejo estético. O que procurarei a seguir, recuperando as idéias expostas até aqui, é elaborar uma hipótese tão geral e inespecífica quanto possível para o fenômeno.

10 Pode-se sugerir algum tipo de atrator ou gramática que restringe as ocorrências neuronais a um determinado espaço de estados. Quando a configuração de disparo neuronal alcança aquele padrão específico já potencialmente disperso no cérebro, suas conseqüências se dão a conhecer. 
Numa primeira aproximação e simplificando bastante, posso dizer que o que temos inicialmente são variações emocionais resultando em sentimentos que vão do desagradável ao agradável, da dor ao prazer, e vice-versa. Desde o seu nascimento o organismo humano empenha-se e está capacitado para gerenciar sua sobrevivência e bem-estar (mesmo que isso dependa de outras pessoas). Impulsos e motivações visam a manutenção do equilíbrio do sistema. Ações que dão lugar a sensações positivas ou agradáveis são marcadas por estas e passam a ser utilizadas nas circunstâncias adequadas. Importante notar que apesar de intimamente ligados, estados de desequilíbrio homeostático não são a mesma coisa que sentimentos desprazerosos. Quando uma região específica do cérebro de um bebê detecta a diminuição preocupante do nível de energia disponível (desequilíbrio homeostático) um dos resultados é a sinalização dessa diminuição para outro sítio cerebral tendo como consequência a sensação de fome. Esta, por sua vez, é sinalizada para ainda outras regiões cerebrais as quais fazem, por exemplo, o bebê chorar escandalosamente. Suponho, apenas, que a região cerebral mais imediata responsável pela emergência da sensação de fome e do comportamento choroso é constituída por um registro ou padrão neural dispositivo que só é acionado em função da sinalização específica oriunda do sítio cerebral que detectou o baixo nível energético. Vale dizer que a sinalização recebida disparou um padrão de ativação neural potencial ou dormente, o qual incluía entre seus comandos virtuais, a atualização de coisas como sensações desprazerosas e o conjunto de rotinas que resulta em um choro expressivo e chamativo. O que desejo ressaltar aqui é, de um lado, o fato de que já nascemos com alguns padrões neurais dispositivos programados geneticamente e, de outro, o modo específico como estes são acionados. Como afirmado anteriormente um registro dispositivo dispara seus comandos quando o conjunto de neurônios e sinapses que o constituem entram em um determinado padrão ou modo de funcionamento específico, a um determinado ritmo, num determinado intervalo de tempo e em direção a um alvo particular. O que se mostra particularmente surpreendente e difícil de explicar é por que determinado estímulo ou objeto tem a capacidade de acionar, de dar lugar àquela configuração multidisparadora. O processo de constituição de padrões neurais dispositivos é hipercomplexo, mas envolve provavelmente disposições inatas, marcadores somáticos, crenças e concepções éticas. O despertar de um registro dispositivo dormente está relacionado com os padrões neurais formados a partir da percepção sensível, tendo cada um sua própria especificidade. A música dita um 
ritmo, uma sequência, a pintura tem seus matizes, cada uma das formas estéticas cria no ambiente cerebral um padrão de ativação ao qual está associada, nos casos mais felizes, a uma série de disparos e acionamentos que envolvem a liberação de neurotransmissores, a ativação do sistema límbico, do sistema de recompensa, a mudança do processamento cognitivo, etc.

Em uma segunda aproximação mais específica, detalhada e retomando a distinção entre a formação e o disparo de um registro dispositivo, apresento agora minha hipótese do processo na base da emergência de uma pequena experiência estética imediata qualquer. X interage, entra em contato, percebe, encontra um estímulo, objeto ou situação. Em seus córtices sensórios (visuais, táteis, olfativos, auditivos, motores) formam-se representações ou padrões neurais consistentemente relacionados ao estímulo percebido. Padrões neurais topograficamente organizados são criados ou recuperados em íntima correspondência com o objeto mapeado, na quantidade e locais que as modalidades sensórias envolvidas exigirem. Acompanho Damásio e chamo essa etapa de estágio de presentificação.

Em seguida, quase imediatamente (e graças a um mecanismo préprogramado responsável pela transmissão e disponibilização global de informação no interior do cérebro) sinais dos vários padrões neurais presentificados são enviados para basicamente duas regiões: o córtex pré-frontal no lobo frontal e a amígdala no lobo temporal, coincidentemente duas das regiões responsáveis pelo disparo emocional e pelas zonas de convergência. Sugiro que ao chegarem a esses locais, em vez de simplesmente "despertarem" um registro dispositivo dormente, os vários sinais vão pouco a pouco (mas muito rapidamente) formando uma configuração de disparo e interação, um padrão específico de ativação neuronal. Eis que esta configuração ou padrão posto em atividade corresponde mais ou menos precisamente a um registro de registros dispositivos ou a um hiper-registro dispositivo construído anteriormente. Proponho chamar essa etapa de estágio de atualização ou emergência do hiperespaço dispositivo (o disparo emocional de Damásio estaria incluindo aqui).

Uma série de comandos está associada à ocorrência deste. Da amígdala partem instruções específicas que induzem nos sítios de execução emocional (hipotálamo, tronco cerebral, etc.) a ativação de outros registros dispositivos, que por sua vez causam mudanças reais no corpo: arrepios, contrações musculares, taquicardia, aumento do fluxo sanguíneo etc. Do córtex pré-frontal seguem sinais para o córtex somatos- 
sensório (ínsula, S2, hipotálamo, etc.), induzindo mudanças no padrão de mapeamento dos estados do corpo. Ao mesmo tempo,núcleos neurotransmissores são liberados e mudam a eficiência e o estilo dos processos cognitivos. Todas essas mudanças no estado do corpo e da mente são mapeadas no córtex somatossensório, provavelmente atualizando com maior ou menor precisão outro registro dispositivo (talvez um espaço neural dispositivo dado que o sentimento que irá emergir é, na verdade, um feixe de sentimentos). Ao mesmo tempo, o hiperespaço dispositivo faz emergir outros registros dispositivos, tais como pensamentos abstratos, lembranças, imagens mentais de várias modalidades sensórias. Ativados, esses outros padrões neurais funcionam como novos estímulos emocionalmente competentes, reforçando todo o processo. Podemos chamar essa etapa de estágio de execução afetivo-cognitiva (cobre a execução emocional de Damásio).

Finalmente, os novos mapas atualizados dos córtices somatossensórios, influenciados pelas alterações orgânicas e pela sinalização direta advinda do córtex pré-frontal, as características do processamento cognitivo, assim como o estímulo externo disparador inicial do processo, são reunidos em um padrão neural de segunda ordem ${ }^{11}$ e percebidos como uma imagem mental hipercomplexa de qualidade especial: um sentimento estético no caso. A essa etapa do processo denomino estágio de percepção-sensação do sentimento estético ou simplesmente estágio de estetização. O conjunto das etapas constitui o que venho chamando de breve experiência estética instantânea ou Flash Aesthesis. Apesar das muitas etapas e dos inúmeros processos envolvidos (e sem levar em consideração tudo o que não foi dito aqui, as muitas estruturas e funções sobre as quais não falei e que certamente também sustentam o fenômeno), tudo se passa em bem poucos segundos.

11 Ao desenvolver sua teoria da consciência, Damásio (2000) faz a distinção entre padrões neurais de primeira e segunda ordem. A princípio, um sentimento seria o padrão neural de primeira ordem, que consiste na percepção do mapa representativo dos estados do corpo atuais ou simulados. A consciência seria um padrão neural de segunda ordem, que reuniria os padrões neurais de primeira ordem do sentimento e do objeto externo percebido e disparador inicial do sentimento em jogo. A consciência seria um sentimento de um sentimento. Por outro lado, sentir um sentimento exige necessariamente a consciência. Nesse sentido, pareceu-me mais adequado assumir que o sentimento estético é já em si um padrão de segunda ordem e não "apenas" a percepção de padrões específicos de atividade neuronal nos córtices somatossensórios. Não podendo ou devendo me aprofundar sobre o tema aqui, e reconhecendo a imprecisão da minha proposição, opto pelo que me parece mais abrangente e inclusivo para posterior especificação. 
O sentimento estético, esse misto de alegria, prazer, sensação de beleza, desejo e vivacidade, que compõe algumas das nossas experiências estéticas, é portanto resultado de um encontro particularmente feliz. O encontro de um estímulo com um hiperespaço dispositivo. Este, no entanto, não é algo estático, fixo ou acabado. É, ao contrário, um conjunto de padrões de ativação neuronal em permanente construção. Não estou certo quanto ao mecanismo por trás da formação de hiperespaços dispositivos. Estes, contudo, parecem sem dúvida alguma constituir artifícios biológicos que facilitam a emergência de experiências gratificantes e intensas. Ao criar no organismo um "signo" que ao ocorrer necessariamente incita a ocorrência de outros signos, o organismo encontra uma maneira prática para prover seu bem-estar e para assinalar na sua consciência a presença de algo valoroso e importante.

Pretendo desenvolver essa hipótese posteriormente, mas a pretexto especulativo e retomando o que sugeri mais acima sobre o assunto, imagino que um hiperespaço dispositivo ganha certa estabilidade e identidade nos córtices pré-frontais e límbicos ao reunir em zonas de convergência os sinais emitidos pelos padrões em atividade, simultaneamente nas várias outras regiões cerebrais durante determinada experiência perceptiva. Imagino também que nem todas as integrações convergentes constituam registros dispositivos reatualizáveis. Muitas percepções sensíveis simultâneas que experimentamos não chegam a criar a conectividade necessária para serem retomadas em conjunto. Que imagens de diferentes modalidades sensórias, pensamentos e percepções do corpo venham a constituir um registro dispositivo, talvez dependa da "força" das conexões entre os padrões que os constituem.

No caso dos hiperespaços dispositivos inatos é mais fácil especular. Podemos dizer que determinado estímulo percebido e representado em um córtex sensório envia seus sinais a uma zona de convergência ativando lá um registro de registros pré-programado, que conta entre suas propriedades a de induzir padrões específicos de disparo em uma série de outros sítios, com resultados previsíveis. Quando um ser humano macho heterossexual (antes mesmo da adolescência e da puberdade) vê uma certa imagem feminina, por exemplo. Em alguns casos essa percepção é suficiente para disparar uma série de reações somáticas e cognitivas. O garoto pode ter as pupilas dilatadas, pode sentir arrepios pelo corpo, associar muitas sensações e pensamentos, eventualmente ficar excitado e até "apaixonado". E tudo isso graças apenas a uma imagem percebida. Esse parece ser o caso típico da ativação de um hiperespaço dispositivo. Um padrão específico de ativação neural na amíg- 
dala, por exemplo, faz com que sítios executores provoquem mudanças específicas no estado das vísceras, do meio interno e da musculatura esquelética, faz com que hormônios e neurotransmissores sejam liberados, altera o processamento cognitivo, induz certos pensamentos, etc. O resultado é um sentimento tão intenso quanto fugaz.

E nossas reações estéticas seriam também inatas? É provável que não. Nossas preferências inatas orientam a formação de nossos hiperespaços dispositivos estéticos, mas estes não devem estar previstos no código genético (mesmo porque os estímulos que irão dispará-los muitas vezes ainda nem sequer foram criados). O prazer e a sensação de beleza que $\mathrm{X}$ sente rapidamente quando observa um quadro de Mark Rothko, por exemplo, é resultado da ativação de quê? Melhor perguntando, para fixar a dúvida: como foi se formando em $\mathrm{X}$ um espaço neural dispositivo pronto a disparar diante de certas composições abstratas? Muitas ainda seriam as especulações possíveis, mas mesmo estas precisam amadurecer. Parte da resposta já está sugerida nos processos descritos anteriormente. O fato é que certos estímulos põem em atividade uma configuração neuronal específica que tem entres suas propriedades a capacidade de disparar uma série de outros registros dispositivos, que em última instância dão lugar a uma breve experiência estética automática.

\section{Conclusão}

O que está em jogo na presentificação, emergência, execução e percepção/sensação estéticas além da liberação de neurotransmissores específicos, sinais eletroquímicos e mudanças somáticas e cognitivas é uma espécie de intercomunicação configuracional, um homeomorfismo ou isomorfismo plurissemiótico. Para todos os efeitos, Damásio insiste que ter um sentimento é perceber, na forma de uma imagem mental, a configuração neural na base desta.

Porque todos os sentimentos contêm algum aspecto de prazer e dor como ingrediente necessário e porque as imagens mentais que nós chamamos de sentimentos emergem de padrões neurais exibidos em mapas corporais, é razoável propor que dor e suas variantes ocorrem quando os mapas corporais do cérebro têm certas configurações. Da mesma maneira, o prazer e suas variantes são os resultados de certas configurações de mapas. Sentir prazer ou sentir dor consiste em ter processos biológicos nos quais a imagem do nosso 
corpo, como descritas nos mapas corpóreos do cérebro, é conformada em um

certo padrão. (...) Mapas de uma certa configuração são as bases para os estados mentais que chamamos de alegria e suas variações, algo como uma marca composta na chave do prazer. Criando um padrão particular de atividade dentro dos mapas corporais. (Damásio 2003: 123-4; 137, grifos meus).

Imagens, sons, movimentos possuem configurações próprias; representações topograficamente organizadas recriam de algum modo essas configurações nos córtices sensórios; estas são sinalizadas para zonas de convergência, dando lugar a um padrão de ativação igualmente dotado de uma configuração. A possível semelhança ou coerência entre essas distintas configurações semióticas parece constituir um dos principais aspectos a aprofundar. Trata-se de compreender a íntima relação estabelecida entre sentimento e forma. Forma externa, visual, em um quadro abstrato, por exemplo; forma interna, neural, em um córtice sensório; forma do mapa somatossensório ou a forma do sentimento.

Do mesmo modo que o artista ou a natureza seleciona os elementos, estruturas e substâncias que irão compor sua obra, o corpo igualmente, ao entrar em contato com esta, seleciona entre suas composições neurais aquelas que melhor parecem "recriar", no ambiente orgânico, o "significado" da mesma. Em boa medida é a própria obra ou estímulo competente que opera a seleção.

Os padrões neurais correspondentes a (uma) cena (...) são construídos de acordo com as regras do próprio cérebro, e são alcançados/obtidos por um período breve de tempo nas regiões sensórias e motoras do cérebro. A construção desses padrões neurais é baseada na seleção momentânea de neurônios e circuitos engajados pela interação. Em outras palavras, os blocos de construção existem dentro do cérebro, disponíveis para serem pinçados selecionados e reunidos em um arranjo particular. (...) Existe um conjunto de correspondências obtido na longa história da evolução entre as características físicas dos objetos independentes de nós e o menu de possíveis respostas do organismo. A relação entre as características físicas dos objetos externos e os componentes a priori que o cérebro seleciona para construir uma representação são importantes questões a serem exploradas no futuro. O padrão neural atribuído a um certo objeto é construído de acordo com o menu de correspondências através da seleção e reunião de ocorrências (tokens) adequadas (Damásio 2003: 199-200).

Inúmeras são hoje as pesquisas que visam a compreender a percepção e criação artísticas e a experiência estética dos pontos de vista biológico, evolutivo, experimental. Ao longo da redação deste artigo mui- 
tos foram os papers encontrados que evidenciaram uma certa confluência de pensamento. Entre estes destaco Epstein (2003) e Thomsen (s/d). Livros com investigações dos substratos neurofisiológicos na base da fruição de formas artísticas específicas também se multiplicam: Jourdain (1998) e Zeki (1999), só para citar alguns exemplos. A estética corpo-dependente ou experimental não é nova, mas parece estar crescendo em todo o mundo. Os referenciais avançados aqui representam apenas mais um viés de uma imensa e complexa investigação. Muitos nexos e abduções ainda podem ser extraídos destes. Muitas lacunas explicativas permanecem, igualmente. Três em particular. A relação entre uma configuração neuronal de um mapa somatossensório e a qualidade de um sentimento que experimentamos subjetivamente; o desenvolvimento dos hiperespaços dispositivos estéticos; e o "despertar" destes diante de certos estímulos.

BISPO, R. Flash Aesthesis: a neurophilosophy of aesthetic experience. Trans/ Form/Ação, (São Paulo), v.27 (2), p.113-142, 2004.

- ABSTRACT: Following text places in dialogue or applies to a certain conception of aesthetic experience a vast set of experimental evidences extracted from the inquiry of other mental phenomena, in particular the subjective experience of emotions and feelings. Comimg from António Damásio the beam master, the skeleton, the base, the structure of all my argument. My main hypothesis is that certain objects and situations activate cerebral dispositional hyper-spaces associated to the ocurrence of phenomena like sensation of beauty, pleasure and joy. I consider that the emergency of an aesthetic experience must be understood as resulted of a sensible perception that set in motion a somatic-cognitive routine function of the detonation of a pattern of dispositionals neural patterns.

- KEYWORDS: aesthetic experience; feeling; dispositional hyper-space; neurophilosophy; brain

\section{Referências bibliográficas}

BEDNAR, J. A. \& MIIKKULAINEN, R. Self-Organization of Innate Face Preferences: Could Genetics Be Expressed Through Learning? In: Proceedings of the Seventeenth National Conference on Artificial Intelligence. Cambridge, MA: MIT Press, pp. 117-122. 2000. 
CHURCHLAND, P. S. Neurophilosophy: Toward a Unified Science of Mind/Brain (Computational Models of Cognition and Perception). Cambridge: The MIT Press, 1986.

DAMÁSIO, A. R. Looking for Spinoza: Joy, Sorrow and the Human Brain. Orlando: Harcourt, 2003

O Mistério da Consciência. São Paulo: Companhia das Letras, 2000.

O Erro de Descartes. São Paulo: Companhia das Letras, 1996.

EPSTEIN, R. Consciousness, art and the brain: Lessons from Marcel Proust. http://wernicke.ccn.upenn.edu/epstein_web/epstein_proust_prepub.pdf Acessado em 17 de dezembro de 2003.

FUSCO, R. Introdução à Experiência Estética. Rio de Janeiro: Departamento de Imprensa Nacional, 1952.

JOURDAIN, R. Música, Cérebro e Êxtase: como a Música Captura nossa Imaginação. Rio de Janeiro: Objetiva, 1998.

KANDEL, E. R., SCHWARTZ, J.H., JESSEL, T.M. Principles of Neural Science. Fourth Edition. New York: Mc Graw Hill, 2000.

LEDOUX, J. O Cérebro Emocional: os misteriosos alicerces da vida emocional. Rio de Janeiro: Objetiva, 1998.

PEREIRA JÚNIOR, A. \& HAASE, V. G. Introdução à Filosofia da Neurociência Cognitiva. In: GonZALes, Maria Eunice Q. et al. (ed.) Encontro com as Ciências Cognitivas. v.1. $2^{\mathrm{a}}$ ed. Marília: UNESP - Faculdade de Filosofia e Ciências, pp. 143-157. 1997.

RAMACHANDRAN,V.S. \& HIRSTEIN, W. The Science of Art: a neurological theory of aesthetic experience. Journal of Consciousness Studies: controversies in science \& the humanities. Vol. 6, N. 6-7, pp. 15-51. 1999.

RHODES, G., GEDDES, K., JEFFERY, L., DZIURAWIEC, S. e CLARK, A. Are average and symmetric faces attractive to infants? Discrimination and looking preferences. Perception. Vol. 31, pp. 315-321. 2002.

THOMSEN, K. Beauty and Art Arise in the Brains of Beholders. <http://cogprints.ecs.soton.ac.uk/archive/00000857/00/beauty.htm> Acessado em 17 de dezembro de 2003.

ZEKI, S. Inner Vision: An Exploration of Art and the Brain. Oxford; New York: Oxford University Press, 1999. 